\title{
The Once-Only Principle: A Matter of Trust
}

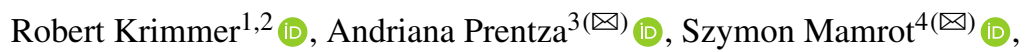 \\ and Carsten Schmidt ${ }^{1,2(\bowtie)}$ (iD
}

${ }^{1}$ Ragnar Nurkse Department of Innovation and Governance, Tallinn University of Technology (TalTech), Akadeemia tee 3, 12618 Tallinn, Estonia

\{robert.krimmer, carsten.schmidt\} ataltech.ee

2 Johan Skytte Institute for Political Studies, Center for IT Impact Studies, University of Tartu, Lossi 36, 51003 Tartu, Estonia

\{robert.krimmer, carsten.schmidt\}@ut.ee

3 Department of Digital Systems, University of Piraeus Research Center, 18532 Piraeus, Greece aaprentza@unipi.gr

${ }^{4}$ Łukasiewicz Research Network - Institute of Logistics and Warehousing, ul. Estkowskiego 6, 61-755 Poznań, Poland

szymon.mamrot@ilim.lukasiewicz.gov.pl

\begin{abstract}
The Single Market is one of the cornerstones of the European Union. The idea to transform it into a Digital Single Market (DSM) was outlined several years ago. The EU has started different initiatives to support this transformation process. One of them is the program Horizon 2020 to support the process from a technical point of view. In parallel to this, initiatives were started to set up a sound legal framework for the DSM. The Single Digital Gateway Regulation (SDGR) is an outcome of these initiatives. The key aspect of the SDGR is the underlying Once-Only Principle (OOP), outlining that businesses and citizens in contact with public administrations have to provide data only once. "The OnceOnly Principle Project (TOOP)" is the EU-funded project initiated for research, testing, and implementation of the OOP in Europe. The authors give an overview of the research questions of the different parts of TOOP. Besides that, they introduce the other chapters of this book and what the reader can expect as the content of them.
\end{abstract}

Keywords: Once-only Principle $\cdot$ Single digital gateway $\cdot$ SDGR $\cdot$ Digital single market $\cdot$ TOOP $\cdot$ Building blocks $\cdot$ e-Delivery

\section{Introduction}

The TOOP Book aims to describe and document the developments and results of the Once-Only Principle Project (TOOP). The once-only principle (OOP) is a concept in the broader context of e-government that aims to ensure that business, citizens, and other organisations have to provide specific information to administrations and governmental authorities only once. The principle was defined as one of the key enablers for e-Government in Europe by the Tallinn Declaration on e-Government at the ministerial meeting during the Estonian Presidency of the Council of the EU on 6 October 2017.

(C) The Author(s) 2021

R. Krimmer et al. (Eds.): The Once-Only Principle, LNCS 12621, pp. 1-8, 2021.

https://doi.org/10.1007/978-3-030-79851-2_1 
However, these exchanges require public administrations to have a certain degree of trust in each other, which is built on a shared legal basis. Together with the organisational and technical concepts of the OOP, the first time in the history of the EU, a specific horizontal, non-sector legal framework for the direct exchange of digital evidence between public administrations in different Member States and associated countries was created. This legal basis for the EU is the Single Digital Gateway Regulation.

TOOP was launched by the European Commission in January 2017 within Horizon 2020 research and innovation programme. The approach of the EC, Member States and associated countries was to introduce TOOP as the large-scale project for research, testing and implementation of the OOP in Europe.

The main objective of TOOP was to explore and demonstrate the OOP across borders, focusing on data from businesses. The OOP is one of the underlying principles stated in the European Union's eGovernment Action Plan 2016-2020, as well as the Single Digital Gateway Regulation. The application of the OOP is the prerequisite for building modern and user-friendly digital services. An important concept to realize the OOP is from a technical point of view the interconnection of base registries. Such registries are defined as being the consolidated source of information for specific domains, such as business, properties, persons, etc. The concept of OOP then means using base registries as information sources that always keep the latest version, and that can provide information on request or subscription. To explore and demonstrate the functionality of OOP, multiple pilots have been selected, and a set of guiding concepts as well as appropriate methodologies are developed. The TOOP project ran pilots in three different domains, General Business Mobility (GBM), Maritime, and eProcurement, in fifteen Member States:

In the GBM pilot, it is considered that a Legal or Natural Person requires data about their company to use in a service, e.g., to issue a certificate for their company

In the Maritime pilot, it is considered that a Legal or Natural Person requires a certificate for their or their company's ship and crew

In the eProcurement pilot, the objective is to get qualification evidence from a data provider for economic operators that are submitting a tender

To support the active or interested partners in piloting, a generic reference architecture for TOOP (TOOPRA) was developed. A reference architecture is a set of standardized enterprise Architectures that provides a frame of reference for a particular domain, sector, or field of interest [1]. The TOOPRA is offered to be used by architects responsible for the design of cross-border solution architectures.

During the lifetime of the project more than 50 organisations from more than $20 \mathrm{EU}$ Member States and associated countries were part of the TOOP consortium, including a number of academic and research institutions. ${ }^{1}$

Caused by the number of partners in the project, a specific structure was developed to ensure on the one side the participation and involvement and on the other side to keep the administration simple and manageable. The partners of the TOOP consortium participated in the project as so-called national consortia via a lead beneficiary. The

\footnotetext{
${ }^{1}$ The number of participating countries and partners has changed over the duration of the project.
} 


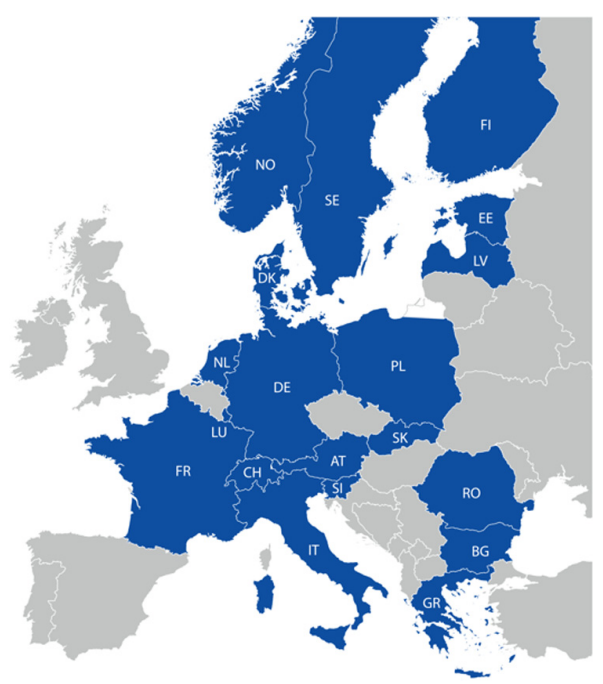

Fig. 1. Map of Countries Participating in TOOP (at the end of the project)

ultimate decision-making body of the project was the General Assembly. Each consortium/beneficiary had one vote in the assembly. The decisions were prepared inside the national consortia based on the rules given to them. The outcomes of this process set the guidelines for the Management Board responsible for the execution of the decision and the maintenance of the daily business of the project. The Management Board consisted of the leaders of the different work packages and the Project Director, as representative of the Project Coordinator.

The participation of different European countries has enabled the exchange of national experiences, and best practices followed intensive discussions on the interoperability issues. The testing activities demonstrated the feasibility of cross-border application and revealed room for further research. Taking into consideration the experience gathered in the field of OOP, the TOOP partners developed several scientific papers covering various aspects of the project. The articles discuss findings from over 4 years of research in the OOP area and are based on the lessons learned in the project.

\section{Overview of Large-Scale Piloting in Europe}

TOOP has not started from scratch. As already stated in the preface of the book, the TOOP project was another project in the long row of so-called "Large-Scale Pilot Projects" (LSPs) initiated by the European Commission with the support of the Member States and associated countries. The large-scale piloting and the preparation of the corresponding setting were initiated at the beginning of the $21^{\text {st }}$ century. A dialog was commenced on the European level between the European Commission (EC) and the Member States. As the outcome of this fruitful collaboration, the preparations for the LSPs took place in 2005. During these groundworks, the main areas were identified as worthwhile for further investigation; eID, eProcurement, and eHealth. They got financial contributions based on 
the ICT Policy Support Programme (ICT PSP), one of the three specific programmes of The Competitiveness and Innovation Framework Programme (CIP) of the EU. Inspired by the success of these initial LSPs, further projects were initiated. As the first step, some additional vertical (sector-specific) projects were kicked off. The focus of these projects was set on the support of the Points of Single Contact in the EU and the area of e-Justice. As a second step within the EU horizontal (cross-sector) projects were introduced, one of the projects (e-SENS) focussed on the technical aspects of a generic cross-border data exchange, and the other project (TOOP) concentrated additionally on the policy aspects of the data exchange.

Some of the previous LSPs had a strong influence on the TOOP project. TOOP used the outcomes of these projects as a foundation for its own work and developments. Especially the following existing LSPs supported by the European Commission produced - mainly technical results - that were re-used for the purpose of the TOOP project. These solutions were developed for different domains, STORK/STORK2.0 for the eID domain; PEPPOL for the eProcurement domain; SPOCS for the Business start-up domain; epSOS for the eHealth domain; and e-CODEX for the e-Justice domain, as well as by the e-SENS project, which aimed to consolidate and align results of the five LSPs.

- The STORK and STORK 2.0 have developed and piloted an interoperability infrastructure for electronic identities.

- The PEPPOL Project would facilitate EU-wide interoperable public eProcurement.

- The overarching goal of the SPOCS Project was to establish a next-generation Point of Single Contact (PSC).

- The epSOS Project was an Open eHealth initiative for piloting patient summary and electronic prescription services

- The e-CODEX Project aimed to provide cross-border interoperable e-Justice infrastructure for the Member States.

- The e-SENS Projects objective was to strengthen the Single Market by facilitating and promoting interoperable public services across borders based on the existing and previous Large-Scale Projects results. This objective comprised planning and design of sustainability and long-term governance of the LSP building blocks, such as e-ID, e-Signatures, e-Documents, and e-Delivery.

\section{Overview of the TOOP Book}

During the lifetime of the TOOP project it become clear that there is not much literature about the OOP aside of the papers that are produced by the members of the project [2-8].

Therefore, it was the main motivation for this book to provide information from the context of the TOOP project to enable or deepen the discourse amongst policymakers, researchers, administrators, and vendors so that understanding, cooperation, future research, and development can emerge. As such, this book consists of 12 chapters that cover the following topics:

\subsection{Implementation of the 'Once-Only' Principle in Europe}

The implementation of OOP on the national level is one of the corner stones of the initiatives around OOP and the SDGR. This article presents the OOP definition and 
discusses the most important EU initiatives to make it a reality in Europe. Furthermore, the chapter of Szymon Mamrot and Katarzyna Rzyszczak provides an overview of national OOP implementations of EU Member States and European Economic Area countries and the related aspects. The analysis focuses on the different stages and different kinds of implementation of the OOP in Europe. It will highlight the states of play in different countries and the (first) outcomes of implementing the OOP.

\subsection{Drivers, Barriers, and Opportunities}

Drivers and barriers are playing an essential role for the implementation of the OOP in Europe. To support the ongoing transition of the SDGR into reality in the different countries, an analysis within several Member States and associated countries based on the experiences and findings within the TOOP project was initiated. This chapter focuses on the identification of influencing factors that are more prevalent in one area than another. The authors Nele Leosk, Irma Põder, Carsten Schmidt, Tarmo Kalvet, and Robert Krimmer furthermore investigated the institutional factors to be the most influential on the OOP implementation. In general, the most important drivers, barriers, and also opportunities that are identified discovered in the TOOP project are summarized here.

\subsection{Good Practices of OOP Across Europe}

Besides the more theoretical approaches of other chapters, it is also essential to give practical information and to highlight good practices related to the OOP in Europe. Maria Wimmer sums up the findings from the OOP good practice analysis, good practice cases, and enablers in different countries. Besides that, an examination of the strategic policies in Europe, the OOP visions, top-down implementation of digitalization, and the bottom-up engagement of stakeholders will be given. On top, there is a look into further projects that are dealing with the OOP, like the DE4A project and the SCOOP4C project.

\subsection{Impact of the Once Only Principle for Businesses Across Borders}

An essential part of the analysis around the once-only principle is especially its impact during and after the implementation. As the OOP is relatively new, the information about the impact of the OOP on businesses, and in particular on its cross-border impact is limited. In this chapter, Tjerk Timan, Anne Fleur van Veenstra and Kristina Karanikolova explore an impact assessment framework for measuring the impact of the OOP on crossborder services for businesses. The outcomes of the measurement for business but also other related actors, e.g., governments will be displayed. Besides that, the validation of this framework with members from the TOOP project will be described. The authors also provide an insight into the preparation and execution of the validation process.

\subsection{The Single Digital Gateway Regulation and Other Legal Aspects}

As the OOP is strongly related to its legal bases, it is crucial to look at the legal framework for the OOP on a national and supranational level. Hans Graux provides a specific chapter 
with an insight into the Single Digital Gateway Regulation as the common legal basis for the EU, its Member States, and the EFTA countries. As part of the description, the requirements for public administrations are highlighted and how especially which role the trust in each other for the success of the OOP plays.

To complement the picture drawn from the European level, a specific focus on the national legal framework is set by Francesco Gorgerino. This study presents how the OOP is related to the constitutional and institutional principles concerning the good performance and impartiality of public authorities and the protection of citizens' rights against the action of public administration, with special regard to the Italian regulatory framework and an additional look into the legal impact of the OOP for development of the European digital single market and in public procurement.

\subsection{Architecture}

A stabile technical architecture is a core pillar for the success of developing and piloting the technical solutions of each project. As TOOP has not started from scratch and is re-using the outcomes of previous LSPs and technical building blocks provided by the EC it is even more critical and difficult to provide an architecture that covers the need of all interested parties. Part of the activities was to assist the members of TOOP and further partners that are concerned in the cross-border implementation of the OOP. The chapter of Jaak Tepandi, Carmen Rotuna, Giovanni Paolo Sellitto, Sander Fieten, and Andriana Prentza outlines the TOOP Reference Architecture (TOOPRA) users, principles, and requirements presents an overview of the architecture development, describes the main views of TOOPRA, discusses architecture profiling, and analyses the TOOPRA sustainability issues.

All kinds of information need to be secured. The level of security needed is directly related to the sensitivity of the data exchanged. As for the OOP, the very sensitive data from base registries are provided, the success of the project is directly bound to the trust in the data. As follow-up, in the chapter of Jaak Tepandi, Luca Boldrin, and Giovanni Paolo Sellitto, the TOOP trust architecture is presented, starting from a simple abstract model of interaction between two agents down to the detailed end-to-end trust establishment architecture, modeled onto the TOOP Reference Architecture.

\subsection{Testing Methodology for the TOOP Pilots}

Testing is vital for the development of a sound technical basis for the OOP. Therefore, already in an early stage, the members of the TOOP project have agreed on the approach for the piloting of the OOP and the area where the piloting is taking place. The goal is to uncover errors and gaps in program function, behaviour, and performance. Andriana Prentza, Marie-Laure Watrinet, and Lefteris Leontaridis describing how the testing methodology was developed and implemented. Besides that, an overview of the set of testing tools created to facilitate testing between the different parties in the three different piloting domains is given.

Furthermore, the generic definition and adaption of the testing methodology for each of the pilot is described. This includes the whole process, how it is started from a 
low level, and how it finishes at a higher level by a particular approach by testing the connections between the different partners within the same piloting domain.

\subsection{Pilot Experiences: Challenges and Achievements in Implementing Once-Only}

Piloting is the proof of the pudding for each project. On the other side, piloting is a complex endeavor where a number of actors and related stakeholders cooperate and interrelate to implement technical solutions that facilitate business processes in new ways. TOOP, as an LSP, required a set of work processes to be defined and a number of procedures and tools to be used by the participating entities to implement the planned activities in ways that achieve results of maximum value that fulfill the objectives of the project. In order to explore and demonstrate the functionality of OOP, multiple pilots have been selected, and a set of guiding concepts as well as appropriate methodologies were developed. Andriana Prentza, David Mitzman, Madis Ehastu, and Lefteris Leontaridis present in the chapter the three different pilot workgroups, General Business Mobility, e-Procurement, and Maritime, that are selected for the demonstration. The advances that are attained are highlighted and also details about the lessons learned are provided.

\subsection{Future of the Once-Only Principle in Europe}

The sustainability of the results of a project like TOOP is of utmost importance. Therefore, after a decent and detailed overview of the developments in and along the lines of the TOOP project is given, to complete the picture, an outlook into the future of the OOP is provided by Robert Krimmer, Andriana Prentza, Szymon Mamrot, Aleksandrs Cepilovs, and Carsten Schmidt. Part of the outlook is a summary of the conclusions of the main parts of this book. It includes an overview of the results of TOOP as a project and the different chapters, e.g., drivers and barriers, impacts, legal and technical aspects, piloting methods and outcomes, and the gaps that are discovered by the project members. This compendium is the basis for the outlook into the future of the OOP and the suggestions for the next steps on the EU- and national level.

\section{The Once-Only Principle and the Further Development of the Single Digital Gateway}

This book with its multidisciplinary chapters published by summer 2021 at the end of TOOP is ideally suited to provide foundation for the further developing of Europe's Single Digital Gateway as outlined before. With the Implementing Act just to be published for the technical system in line with Article 14 SDGR, it sets the scene for an incredible next step in the digital transformation of Europe: Providing seamless cross-border digital public services in just some 2,5 years. May these following chapters provide you with the insights needed for the intense work to come! 


\section{References}

1. Proper, H.A., Lankhorst, M.M.: Enterprise architecture.- towards essential sensemaking. Enterp. Model. Inf. Syst. Architect. Itextbf $\{9\}(1), 5-21$ (2014)

2. Wimmer, M.A., Neuroni, A.C., Frecè, J.T.: Approaches to good data governance in support of public sector transformation through once-only. In: Viale Pereira, G., et al. (eds.) EGOV 2020. LNCS, vol. 12219, pp. 210-222. Springer, Cham (2020). https://doi.org/10.1007/978-3-03057599-1_16

3. Krimmer, R., Kalvet, T., Toots, M.: Contributing to a digital single market for Europe Barriers and Drivers of an EU-wide Once-Only Principle. dg.o '18: dg.o 2018: Proceedings ofthe 19th Annual International Conference on Digital Government Research, May 30-June 1, 2018, pp. 1-8, (2018). https://doi.org/10.1145/3209281.3209344.

4. Cirnu, C.-E., Rotuna, C.-I.: Cross-border eServices for public administration driven by OnceOnly Principle. Revista Română de Informatică și Automatică 30(4), 99-110 (2020). https:// doi.org/10.33436/v30i4y202008S1-12M4-Citavi

5. Siapera, M., Douloudis, K., Dimitriou, G., Prentza, A.: Employing the once-only principle in the domain of the electronic public procurement, pp. 236-246 (2020)

6. Krimmer, R., Kalvet, T., Toots, M., Cepilovs, A., Tambouris, E.: Exploring and demonstrating the once-only principle. In: 18th Annual International Conference on Digital Government, pp. 546-551 (2017) https://doi.org/10.1145/3085228.3085235.

7. Krimmer, R., Kalvet, T., Toots, M.: The Once-Only Principle Project Drivers and Barriers for OOP (2017)

8. Tepandi, J., et al.: Towards a cross-border reference architecture for the once-only principle in Europe: an enterprise modelling approach, pp. 103-117 (2019)

Open Access This chapter is licensed under the terms of the Creative Commons Attribution 4.0 International License (http://creativecommons.org/licenses/by/4.0/), which permits use, sharing, adaptation, distribution and reproduction in any medium or format, as long as you give appropriate credit to the original author(s) and the source, provide a link to the Creative Commons license and indicate if changes were made.

The images or other third party material in this chapter are included in the chapter's Creative Commons license, unless indicated otherwise in a credit line to the material. If material is not included in the chapter's Creative Commons license and your intended use is not permitted by statutory regulation or exceeds the permitted use, you will need to obtain permission directly from the copyright holder.

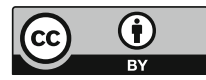

